\title{
PIBID - PRIMORDIAL PARA A FORMAÇÃO DE PROFESSORES
}

\section{Ana Carolina Alves da Silva ${ }^{1}$ \\ Rafael de Siqueira Santos ${ }^{2}$ \\ Rafael Dias Rios de Souza ${ }^{3}$ \\ Thiago Santana Ribeiro ${ }^{4}$ \\ Ana Enedi Prince ${ }^{5}$}

Resumo: Realizamos nesse artigo, reflexões necessárias para as compreensões e os significados relativos ao Programa de Bolsa de Iniciação à Docência (PIBID), cujo objetivo é o de contribuir de maneira significativa para a formação inicial de professores de História. Constatamos que esse programa é compreendido como um espaço que possibilita a integração entre universidade-escola, oportunizando aos futuros professores, o entendimento e a análise sobre a profissão docente e a realidade escolar. Isso ocorre por meio do desenvolvimento de temáticas que priorizam a inserção de diferentes materiais e abordagens didáticas no ensino de história, visando a renovação nesse campo do conhecimento.

Palavras-chave: Educação; PIBID; Projetos Escolares; Formação de Professores e História.

\footnotetext{
${ }^{1}$ História/Universidade do Vale do Paraíba, Brasil. E-mail: carolinaana967@gmail.com.

2 História/Universidade do Vale do Paraíba, Brasil. E-mail: faelsiq@hotmail.com.

3 História/Universidade do Vale do Paraíba, Brasil. E-mail: rafaelrios14@gmail.com.

${ }^{4}$ História/Universidade do Vale do Paraíba, Brasil. E-mail: thiagosantana@live.com.

${ }^{5}$ História/Universidade do Vale do Paraíba, Brasil. E-mail: prince@univap.br.
} 